\title{
Apraxia e silenciar: formas resistência-revolta por meio de uma subtração subjetiva
}

Maurício Beck

\begin{abstract}
Resumen: El lenguaje no sólo clasifica el mundo, pero nos obliga a decir algo sobre ese mundo. No es de extrañar que, en la antigua Grecia, los pirronicos se encontraban en dificultades en su discurso: una vez que postulan la suspensión (temporal) del juicio como postura filosófica, como no predicar al hablar? Según Montaigne, para evitar la trampa de recurrir constantemente a modalizaciones "Yo afirmo que no afirmo," el pirronico tendría que basarse en una lengua distinta, una lengua imaginaria, negativa. Sin embargo, si consideramos el problema desde la perspectiva del Análisis del Discurso, podriamos proponer el silencio como una práctica /apraxia, como forma más efectiva de suspensión del juicio?
\end{abstract}

Palabras-clave: Discurso, silencio, suspension del juicio

Resumo: A língua não somente categoriza o mundo como nos obriga a dizer algo acerca desse mundo. Não é para menos que, já na Grécia Antiga, os pirrônicos encontravam-se em dificuldades em seu discurso: uma vez que postulavam a (momentânea) suspensão do juízo como postura filosófica, como não predicar ao falar? Segundo Montaigne, para evitar a armadilha de recorrer constantemente à modalizações no estilo "afirmo que não afirmo", os pirrônicos teriam de se valer de uma linguagem outra, uma imaginária língua, negativa. Entretanto, se pensarmos essa problemática na perspectiva da Análise de Discurso, poderíamos propor o silenciar, enquanto prática/ apraxia, como forma mais eficaz de suspensão do juízo?

Palavras-chave: Discurso, silêncio, suspensão do juízo

Com a resistência caminha e se levanta um silêncio terrível: o silêncio que acusa e põe o dedo na ferida. EZLN

\section{O Fascismo da Língua}

Gostaria de começar o presente texto retomando a aula inaugural de Roland Barthes no Colégio de França em 1977. Das palavras de Barthes naquele janeiro francês quero

1 Pós-doc FAPERJ/UFF 
partir da sua mais controvertida e famosa asserção "a língua, como desempenho de toda linguagem, não é reacionária, nem progressista, ela é simplesmente: fascista; pois o fascismo não é impedir de dizer, é obrigar a dizer." (BARTHES, p. 14).

O semiólogo francês remonta ao conceito de língua numa base estruturalista, segundo a qual essa é entendida como sistema de signos e um "princípio de classificação" (SAUSSURE, p. 17), ou uma faculdade mais geral, que comanda os signos. De modo que estes não são etiquetas avulsas coladas, conforme uma razão qualquer, aos entes no mundo. Em outras palavras, a língua até pode ter como característica remeter a algo que não é ela mesma (mundo, entes, referente, etc.), mas para remeter a esse algo, necessariamente deve classificá-lo, ordená-lo conforme princípios imanentes de organização significante. É por isso que Saussure pode suprimir o referente no estudo do sistema linguístico, uma vez que a natureza dos "referentes no mundo" não interferem na língua enquanto forma e em suas leis específicas. Não é novidade dizer que na perspectiva com que trabalhamos, (a da Análise de Discurso formulada pelo círculo de intelectuais em torno do filósofo francês Michel Pêcheux entre as décadas de 60 e 70 do século passado), essa autonomia da língua é relativizada, uma vez que está inscrita na história enquanto relações de forças de ordem material, mas deixemos em suspenso essa diferença por ora.

Retomemo-nos às palavras de Barthes ([1978]. 2007):

\begin{abstract}
“A linguagem é uma legislação, a língua é seu código. Não vemos o poder que reside na língua, porque esquecemos que toda língua é uma classificação, e que toda classificação é opressiva: ordo quer dizer, ao mesmo tempo, repartição e cominação. Jakobson mostrou que um idioma se define menos pelo que ele permite dizer, do que por aquilo que ele obriga a dizer. (p.12) [...] a língua é imediatamente assertiva: a negação, a dúvida, a possibilidade, a suspensão de julgamento requerem operadores particulares que são eles próprios retomados num jogo de máscaras linguageiras ; o que os linguistas chamam de modalidade nunca é mais do que um suplemento da língua, aquilo através de que, como na súplica, tento dobrar seu poder implacável de constatação". (p.14, grifos meus).
\end{abstract}

O fascismo da língua em Barthes está por conseguinte imbricado ao caráter enclausurador assertivo da estrutura das línguas. É nessa estrutura obrigatória que o poder se inscreve enquanto "parasita de um organismo trans-social" (Ibid. p. 12) nas palavras do semiólogo.

Entretanto se a imbricação língua\&poder é própria à teoria barthesiana, a questão do caráter assertivo das línguas remonta há bem mais tempo na história das ideias e do pensamento. Remonta por exemplo aos céticos pirrônicos (cuja filosofia foi registrada por Sexto Empírico no séc. II). Para os agora chamados céticos clássicos o caráter assertivo da língua se colocava como um problema, uma vez que os pirrônicos defendiam a suspensão do juízo como melhor postura filosófica para alcançar a felicidade (eudaimonia). Entre duas ou mais teorias ou explicações (filosóficas) conflitantes, os céticos consideravam que não havia como decidir pela verdade. Restava suspender o juízo e esperar por melhores condições de discernibilidade.

Ressalto que a posição almejada pelos céticos clássicos não é a de moderação, que escolheria o "melhor de cada lado". É, antes, uma posição de suspensão do "martelo do juiz". Além disso, a verdade não é tida como eternamente inalcançável para os pirrônicos, pois afirmar a impossibilidade da verdade é também uma asserção dogmática, própria aqueles que os gregos nomeavam acadêmicos (e que corresponderia aos nossos céticos modernos). 
Os céticos se posicionavam a favor da ataraxia (imperturbabilidade) e da afasia (não predicação). Nesse último caso, não se tratava exatamente de nada falar, mas de falar sem predicar. A contradição com que se depararam, segundo El-Jaick (2009) foi de que a "língua da vida comum" (que os céticos preferiam à língua especializada dos teóricos dogmáticos ou acadêmicos) é assertiva, é predicativa. Assim toda modalização acaba recaindo na contradição sintetizada no seguinte oximoro: "não afirmo que afirmo (EL-JAICK, 2009, p. 162)". Para os pirrônicos, haveria a necessidade de outra língua.:

Acreditamos que Sexto [Empírico] use a linguagem comum também quando explica a seus leitores o que é o pirronismo. Por isso, mescla exemplos cotidianos com exemplos filosóficos. Mas como o dogmático existe, o cético precisa retirar toda assertividade do discurso comum. O ideal seria que o cético, como certeiramente enxergou Montaigne, tivesse uma linguagem negativa, de modo que a linguagem do cético fosse oca de assertividade - assertividade que comparece na linguagem comum. (Idem, p. 161).

Nas contradições e armadilhas que ameaçavam a posição de suspensão do juízo no pirronismo já encontramos a estrutura assertiva e obrigatória da língua de que Barthes nos falará mais de mil anos depois do Sexto Empírico ter registrado na história da filosofia essa singular postura que recusa a predicação assertiva e se imiscui em modalizações como a seguinte:

"O mel aparece para nós como doce (e isto nós garantimos, pois nós percebemos doçura através de nossos sentidos), mas se ele é também doce em sua essência é para nós matéria de dúvida, uma vez que isso não é uma aparência, mas um julgamento com relação à aparência". (SEXTUS EMPIRICUS, p. 34)

Apesar desse belo e sutil movimento de não-afirmar-já-afirmando, se acreditarmos em Montaigne e em Barthes, as modalizações são suplementos da língua que não conseguem de todo driblar o que a língua tem de assertivo e obrigatório. Vimos que para Montaigne, a saída seria uma linguagem imaginária negativa.

E na perspectiva discursiva, como poderíamos pensar essa prática da recusa em predicar? Como suspender a predicação?

Ao colocar essa questão para a Análise de Discurso não estou necessariamente corroborando a postura filosófica dos pirrônicos, mas mais interessado em encontrar formas de recusa e de subtração aos ditames obrigatórios da língua na acepção de Barthes. Antes de avançar, porém, é pertinente retomar algumas diferenças teóricas entre a linguística saussureana, a semiologia de Barthes, de um lado, e a Análise de Discurso, de outro. Como já mencionei, se para Saussure, e também para Barthes, a língua é entendida como um sistema dotado de leis imanentes, para a Análise de Discurso, aquela é um sistema com sua regularidade própria, mas cuja autonomia é relativa (para usar a expressão althusseriana). Contudo, o que mais interessa para a presente questão é a diferença na cisão língua/fala. Em Análise de Discurso, não trabalhamos com a noção de fala, mas com a de discurso. E a noção de discurso como a forma de expressão material da Ideologia, forma regulada por um todo complexo com dominante que determina o que pode e deve ser dito a partir de uma posição dada, em dadas condições de produção históricas. Eis certa convergência com a asserção de Barthes, para nós, analistas, não só a língua, mas a prática discursiva por si obriga ou, em outros termos, assujeita aquele que fala a regularidades impostas por 
condições externas. Como afirma Orlandi (2009, p.263), "às relações de poder interessa menos calar o interlocutor do que obrigá-lo a dizer o que se quer ouvir.”.

O que resta a saber é: pode o sujeito se subtrair ao rito discursivo? Uma vez interpelado o indivíduo em sujeito, há possibilidade de recusar a injunção ao dizer (idem, p. 264)? Há como não tomar posição em dado ritual, cujas coordenadas pre-estabelecidas não potencializariam uma ruptura com o funcionamento reprodutivo da ideologia?

As formas de resistência do sujeito por meio de formações inconscientes já nos são conhecidas. Atos falhos, lapsos, chistes são modos de subversão no tempo de um relâmpago em que a insistência do inconsciente emerge e evanesce e faz os rituais falharem (PÊCHEUX, [1978], 1997). Contudo, se desde Althusser entendemos a ideologia dominante como prática que assegura a reprodução das relações de dominação-exploração-segregação por meio de sua repetição incessante, ainda que sujeita à falhas, então não é possível pensar na suspensão, ainda que momentânea, de sua repetição como uma forma de desobediência civil? As formulações de Orlandi sobre as formas do silêncio não permitiriam pensar no silenciar como uma apraxia revoltosa? Eis as pistas que perseguirei daqui por diante: a apraxia e o silenciar. Este último, diferente de calar (que oprime) o outro, definido, segundo Orlandi (idem), como o silêncio do oprimido que resiste à dominação. Pois bem, comecemos pelo silêncio.

\title{
2. Considerações sobre o silêncio
}

Tomo como um oportuno ponto de partida uma citação do filósofo esloveno Slavoj Žižek (2008, p. 209-210):

\begin{abstract}
"O fato primordial não é o Silêncio (à espera de ser quebrado pela Palavra divina), mas o Ruído, o murmúrio confuso do Real, no qual ainda não há nenhuma distinção entre figura e fundo. O primeiro ato criativo, portanto, é criar silêncio - não que o silêncio seja quebrado, mas o próprio silêncio quebra, interrompe, o murmúrio do Real, abrindo assim uma clareira em que as palavras podem ser ditas. Não há discurso propriamente dito sem esse fundo de silêncio: como sabia Heidegger, todo discurso responde ao "som do silêncio" É preciso muito trabalho para criar silêncio, para cercar seu lugar do mesmo modo que um vaso cria seu vazio central."
\end{abstract}

Dentro da perspectiva do filósofo, o silêncio é entendido como produto de um trabalho (humano). Ele é resultado de práticas sociais que constituem um espaço de silêncio delimitado pelo incessante ruído do Real. Parafraseando Churchill, diríamos que o silêncio resulta de muito sangue, suor e lágrimas. Em outras palavras, é fruto de muita disciplina, de muito trabalho (tripalium). Para Žižek, a possibilidade do discurso se abre com o "som do silêncio", sem este só teríamos uma infindável algazarra indisciplinada, um perene murmúrio indistinto.

Não há, por conseguinte, um silêncio in natura. Sendo fruto do trabalho humano, o silêncio, para existir, necessita do que Freud chamava cultura ou civilização. Ou seja, o silêncio emerge no estado desnaturado (artificial) que o homem instaura com suas práticas socialmente coordenadas. O silêncio seria algo como um artefato produzido pelos homens, como o vazio do vaso da analogia žižekiana.

É curioso notar que a cosmogonia dos indígenas do sudeste mexicano (base social dos zapatistas citados mais adiante) pensa o ruído como anterior ao silêncio na aurora do mundo. Com efeito, em um diálogo imaginário do Velho Antônio, personagem indígena sábia e ancestral, com o Subcomandante Marcos (suposto porta-voz zapatista), há a seguinte narrativa: 
"Entonces los dioses se buscaron un silencio para orientarse otra vez, pero no lo encontraban por ningún lado al silencio, a saber dónde se había ido el silencio y con razón porque mucho era el ruido que había. Y desesperados se pusieron los dioses más grandes porque no encontraban el silencio para encontrarse el camino y entonces se pusieron de acuerdo en una asamblea de dioses y mucho batallaron para la asamblea que se hicieron porque mucho era el ruidero que se había y por fín acordaron que cada uno buscara un silencio para encontrar el camino y entonces se pusieron contentos por el acuerdo que tomaron pero no muy se notó porque había mucho ruido. Y entonces cada dios comenzó a buscarse un silencio para encontrarse y empezaron a buscar a los lados y nada, y arriba y nada, y abajo y nada, y como ya no había por dónde buscar un silencio pues empezaron a buscarse dentro de ellos mismos y empezaron a mirarse adentro y ahí buscaron un silencio y ahí lo encontraron y ahí se encontraron y ahí encontraron otra vez su camino los más grandes dioses, los que nacieron el mundo, los primeros." (EZLN, 1997)

O ruído primeiro, entre os deuses dessa cosmogonia ameríndia, impedia o entendimento e dificultava encontrar seu caminho (seu itinerário) em um tempo em que o tempo ainda não se contava. $\mathrm{O}$ silêncio surge como possibilidade de sentido.

Cabe ainda mencionar que a perspectiva de žižekiana acerca do silêncio pode ser uma abordagem interessante para avançar, em uma ótica materialista, a tese empreendida pelo viés da lógica de Tfouni (2008, p. 368.) de que o interdito, como "um operador fundante, constitutivo estruturante e universal da linguagem," teria primazia em relação ao silêncio. Talvez se possa dizer que entre as práticas que engendram o silêncio esteja a do interdito, uma vez que para Tfouni a interdição é condição para o silêncio, enquanto espaço diferencial, e possibilidade do dizer (justamente porque impede o tudo dizer).

\section{O silêncio e seus sentidos}

Neste subcapítulo e no próximo apresentarei alguns excertos atualizados de um capítulo "O Silenciar zapatista: quem cala dissente?"de minha tese de doutorado (BECK, 2010). Trata-se de uma retomada, reformulação e avanço em uma série de questões investigadas naquele outro momento.

Há dois autores historicamente distantes, mas que, de acordo com Auroux (1998), desenvolveram importantes estudos acerca do domínio do silêncio. Estes autores são o abade Dinouart ([1771] (2001)) e Eni Orlandi (2007). Por ora, remonto ao abade, por ser menos conhecido do analistas, no momento do gesto de análise, retomarei as imprescindíveis formulações de Orlandi.

Dinouart é autor de um tratado acerca da Arte de Calar, livro de retórica cristã. Entretanto, para Haroche e Courtine (2001), prefaciadores da versão brasileira do livro, ainda que aborde o silêncio na ótica religiosa católica, Dinouart não discorre sobre o silêncio contemplativo ou sobre o inefável, mas sim sobre a "arte de fazer alguma coisa ao outro pelo silêncio". (HAROCHE; COURTINE, 2001, p. VIII, grifo dos autores). Essa espécie de semiótica do silêncio, na definição de Haroche e Courtine, é permeada por uma ética da prudência atenta às circunstâncias "conforme o tempo e o lugar em que se está no mundo" (Ibid. p. XXX.) e que faz do sujeito calado um engenheiro da ocasião ao conter sua língua (uma vez que haveria na palavra o perigo de uma despossessão de si). Ainda segundo Haroche e Courtine, esta arte da tacita significatio é menos uma arte de governar o outro do que uma forma de resistir a seu domínio. 
O discurso cristão de Dinouart postula um sujeito dotado de livre arbítrio capaz de fazer escolhas efetivas e conscientes entre o bem e o mal. Há, ainda assim, em sua concepção de silêncio algo que ressoa as teorizações da Análise de Discurso. Dinouart não define o silêncio como um vazio de sentidos, como um negativo da linguagem verbal. O silêncio é dotado de potência para afetar os outros sujeitos, afetar a relação (de forças) entre os sujeitos de modo acarretar efeitos políticos.

Na perspectiva aberta por Dinouart (2001, p. 15-16), poder-se-ia interpretar o silenciar como uma cautela, "o silêncio é prudente quando se sabe calar oportunamente, conforme o tempo e o lugar que se está no mundo". Uma forma de silêncio artificioso (tático) com efeitos de surpresa e desconcerto. Um silêncio político porque prudente, "que se poupa, que se conduz com circunspecção, que não diz tudo o que pensa, que nem sempre explica sua conduta e seus desígnios". De todo modo, o silenciar não é intrinsecamente negativo, não constituí um vazio sem significado; pelo contrário, está prenhe de sentidos e de efeitos políticos.

Uma vez apresentadas as formulações teóricas, passo a um breve gesto de análise do silenciar como apraxia cujos efeitos políticos não são negligenciáveis.

\section{O Silenciar Zapatista como exemplo de uma apraxia revoltosa}

Apesar de, ou justamente porque, Exército Zapatista de Libertação Nacional (organização composta majoritariamente de indígenas e localizada no sudeste mexicano), se tornou mundialmente conhecido por meio de declarações, comunicados e cartas desde seu levante armado em janeiro de 1994, numa franca guerrilha de palavras (difundidas, sobretudo, na rede mundial dos computadores), seus inesperados momentos de silêncio foram capazes produzir efeitos de grande alcance político

"O Silêncio tem sido uma das repostas dos zapatistas à estratégia de guerra do governo. [...] Ironicamente, o silêncio do comando se ouve com a mesma força que sua palavra de ontem. Longe de ter perdido espaço na vida política nacional, o zapatismo se mantém, sem publicar uma só frase, no centro da tormenta. "Quem permanece em silêncio é ingovernável”, disse Ivan Illich”. ( NAVARRO, [1998], 2002.)

Essa citação é de junho de 1998, dias após um ataque da infantaria do exército mexicano (com a ajuda de tanques, aviões e helicópteros) ao município de San Juan de la Libertad ou el Bosque - Chiapas, no território autônomo rebelde. A consequência mais dramática do acontecido foram as execuções de rebeldes civis. Somente no mês seguinte (julho de 1998), os zapatistas difundem a Quinta Declaração da Selva Lacandona. Nesse texto, além de explicitar seu posicionamento frente aos acontecimentos, há recorrentes menções ao silêncio do opressor e ao seu silêncio de resistência: este último é significado, da mesma forma que a palavra zapatista, como uma arma:

"Mientras el gobierno amontonaba palabras huecas y se apresuraba a discutir con un rival que se le escabullía continuamente, los zapatistas hicimos del silencio un arma de lucha que no conocía y contra la que nada pudo hacer, y contra nuestro silencio se estrellaron una y otra vez las punzantes mentiras, las balas, las bombas, los golpes. Así como después de los combates de enero de 94 descubrimos en la palabra un arma, ahora lo hicimos con el silencio. Mientras el gobierno ofreció a todos la amenaza, la muerte y la destrucción, nosotros pudimos aprendernos y enseñarnos y enseñar otra forma de lucha, y que, con la razón, la verdad y la historia, se puede pelear y ganar... callando". (EZLN, 1998) 
Entretanto, uma vez que meu escopo é analisar os efeitos do silenciar zapatista e não propriamente o discurso do Exército Zapatista de Libertação Nacional (EZLN) sobre seu silêncio ${ }^{2}$, remontemo-nos aos acontecimentos precedentes e ao intervalo de cem dias de silenciar zapatista. Em março do mesmo ano, ocorreram espancamentos de crianças e encarceramento de mulheres e homens no município autônomo de Tierra y Libertad, em Chiapas, após um ataque do exército mexicano. Também naquele mês, observadores internacionais, presentes na região do conflito armado, foram expulsos do país. Essa ofensiva bélica do governo obstaculizou qualquer diálogo pacífico com os insurgentes zapatistas, ao mesmo tempo em que foi um retrocesso na luta pelos direitos constitucionais dos povos indígenas.

"O desgaste governamental tem sido produto tanto das incongruências internas [...] como do choque desta com os povos em resistência pacífica e com amplas franjas da sociedade civil nacional e internacional. O silêncio zapatista tem incrementado os custos da estratégia oficial. Ao fazer-se invisível ao comando do EZLN, tem evidenciado a verdadeira natureza da ofensiva governamental”. (NAVARRO, [1998], 2002.)

O silenciar zapatista, o hablar callando (cf. o oximoro do EZLN, 1998) permitiu que todos ouvissem a estrondosa ofensiva bélica do governo mexicano. Este "silêncio corrosivo", significou, para todos os sujeitos atentos ao seu repentino mutismo, a violência do antagonista. Por outro lado, para os próprios zapatistas, seu silenciar funcionou como um tempo para “a 'respiração' (o fôlego) da significação; um lugar de recuo necessário para que se possa significar, para que o sentido faça sentido" (ORLANDI,2007, p. 13) Não esquecendo que o EZLN regularmente se retira de cena para consultar as comunidades autônomas chiapanecas por meio de assembleias e conselhos. Além disso, a temporalidade, própria aos indígenas da Selva Lacandona (área de atuação dos zapatistas), possui um ritmo próprio de se significar “que supõe o movimento entre o silêncio e linguagem” (Ibid. p. 25.)

Ademais, para Orlandi, se na linguagem há certa estabilização do movimento de sentidos, no silêncio "sentido e sujeito se movem largamente". ${ }^{4}$ Nessa perspectiva, o silêncio é compreendido como "a matéria significante por excelência, um continuum significante". ( Ibid. p. 27.) Em outras palavras, "o silêncio é. Ele significa. Ou melhor, no silêncio, o sentido é." (Ibid. Grifos da autora.)

Orlandi (2007) confere um estatuto positivo ao silêncio, uma instância antes relegada ao negativo e às margens do verbal (não dito). Definido como instância em que os sentidos e os sujeitos estão em movimento (em que os sentidos $s a \tilde{o}$ ), o silêncio possui consistência ontológica, ou melhor, consistência material. É possível afirmar que no silêncio os direcionamentos ideológicos de sentido se encontram momentaneamente suspensos em suas possibilidades de realização:

\footnotetext{
2 Cf. Artigo de Avilla (S.D.), que tomou como objeto de análise justamente o discurso do EZLN acerca de seu silenciar com vistas a compreender o processo de significação do discurso del silencio. Ademais, nesse artigo, assim como no de Perez (2004) e no de Kohan (2003), constam referências históricas ao silenciar recorrente dos zapatistas no transcurso dos anos. Uma vez que não tive a pretensão de ser exaustivo, tomei somente o supracitado episódio de recusa a dizer para fins de análise.

3 ORLANDI, 2007, p.13. Este efeito político é ressaltado no discurso do EZLN sobre seu próprio silenciar:"Y trajo la guerra el gobierno y no obtuvo respuesta alguna, pero su crimen siguió. Nuestro silencio desnudó al poderoso y lo mostró tal y como es: una bestia criminal. Vimos que nuestro silencio evitó que la muerte y la destrucción crecieran." (EZLN, 1998).

4 Conforme Orlandi, em 'As formas do Silêncio. No Movimento dos Sentidos' (2007)
} 
"A polissemia, nessa perspectiva, é função do silêncio, pois permite a relação - ainda que indireta e sempre mediada - do sujeito com o interdiscurso (a exterioridade). Relação que produz indistinção, instabilidade e dispersão.” (Ibid, p. 158.)

Esse efeito de indistinção ou suspensão parece atuante no silenciar zapatista. Acontecimentos violentos concretos e traumáticos exigem inelutavelmente uma tomada de posição e um trabalho simbólico dos sujeitos (tanto à esquerda, quanto à direita do espectro político mexicano).

Dito isso, cabe lançar algumas questões: uma vez que a ideologia dominante oblitera o antagonismo, então a ideologia antagônica deveria, em contraste, ressaltar tal conflito, questionar as evidências da matriz de sentidos hegemônica. Contudo, e se a crítica ideológica não necessariamente acarretar um efeito político de fortalecimento das posições antagônicas? E se esse efeito já for esperado, se for uma fala silenciadora (ORLANDI, 2009), parte do ritual ideológico? E se essa crítica reconhecida fosse um modo de subtrair a possibilidade de as massas, ousarem pensar por si mesmas ${ }^{5}$ ? Talvez, a injunção por um posicionamento dos zapatistas naquele momento fosse a demanda por uma posição de vanguarda "esclarecida", supostamente portadora de um saber régio ${ }^{6}$ sobre o real do antagonismo social. Demanda essa semelhante àquela, criticada por Althusser (1978), a dos militantes infantilizados pelo Partido Comunista Francês que sempre liam a posição da "linha justa do partido", no jornal do partido, para somente então se posicionarem acerca de dado assunto.

Acredito que, na perspectiva que tratava anteriormente, o modo mais apropriado de suspender o juízo (suspender a categorização da língua ou o direcionamento ideológico dos sentidos) é por meio do silenciar. "O homem nunca é tão dono de si mesmo quanto no silêncio: fora dele, parece derramar-se, por assim dizer, para fora de si e dissipar-se pelo discurso; de modo que ele pertence menos a si mesmo do que aos outros" (DINOUART, [1771] 2001, p. 13.) Em contraste, no silenciar, a movência dos sentidos e a polissemia permanecem possíveis para outros sujeitos, fora do circuito reconhecido de porta-vozes (um sujeito suposto saber político?). O lance de dados se mantém momentaneamente em suspensão, para usar a imagem de Milner, retomada por Tfouni (2008, p. 359)

\begin{abstract}
"Quanto ao dito, no momento anterior ao lançamento dos dados, ele é um conjunto de possibilidades sem limites, correspondendo a um suposto "possível absoluto", mas que seriam possibilidades em suspenso, ou seja, antes do lançamento dizer nenhum pode ser atualizado (vemos aqui a categoria do impossível). No entanto, para que haja enunciação, o corte é necessário, ou seja, é preciso lançar os dados. Com o inevitável (ou necessário) lançar dos dados, o enunciado passa a ser contingente, já que o resultado do lance poderia ser outro, mas é também impossível, porque depois de lançados, não se apaga mais o resultado".
\end{abstract}

Ainda que seja inevitável lançar os dados, ou ainda que diante dos fatos os sujeitos sofram a injunção a dizer e a interpretar, a suspensão momentânea do ritual pelo silenciar (como

\footnotetext{
5 "Ninguém pode pensar do lugar de quem quer que seja: primado prático do inconsciente, que significa que é preciso suportar o que venha a ser pensado, isto é, é preciso 'ousar pensar por si mesmo"” (PÊCHEUX, [1978], 1997, p. 304)

6 Símile à ciência régia, criticada por Pêcheux (2002), que funcionaria na certeza de que "os proletários, as massas, o povo... teriam tal necessidade vital de universos logicamente estabilizados que os jogos da ordem simbólica não os concerniriam!" (ibid, p. 53) Novamente cabe mencionar o discurso do EZLN sobre seu silenciar: "Vimos que, callando, mejor podíamos escuchar voces y vientos de abajo, y no sólo la ruda voz de la guerra de arriba." (EZLN, 1998).
} 
uma forma de auto-interdição?) permite que outros se incumbam de interpretar o lançamento de dados. A interpretação de Avila (s.d.) converge com a minha neste ponto: "El discurso del silencio no es completamente mudo, pues [...] genera la opinión de amplios sectores."

De fato, nesse caso, o silenciar parece potencializar - pela movência dos sentidos e dos sujeitos confrontados com o Real dos antagonismos sociais - interpretações outras, não atreladas a uma referência de vanguarda "esclarecida" que, em termos psicanalíticos, seria algo como "o sujeito suposto saber". Não responder à demanda e furtar-se à injunção a dizer no momento em que o Real do acontecimento ainda não foi submetido à tentativas de simbolização, é um modo de desestabilizar o ritual que rege o direcionamento dos sentidos. Referindo-se a outro episódio de silêncio do EZLN (2001- 2003), Kohan (2003, p. 42) ressalta a relação do silenciar zapatista com atributos específicos dos povos ameríndios:

"Um ano e sete meses de silêncio zapatista não devem surpreender, mas também não devem ser confundidos. O silêncio não significa omissão, complacência ou legitimação. Ele é uma das formas de expressão de muitos povos indígenas em América Latina. É também uma forma de lutar e propagar uma maneira diferenciada de entender o discurso, a fala, a palavra. Os zapatistas o dizem explicitamente: o silêncio é algo que deve ser cuidado e preservado... É uma forma de resistência. É também sinal de uma outra forma de entender e praticar política. Afinal, é outra forma de vida".

Ademais, é preciso não esquecer um aspecto singular na história do levante zapatista. Sua organização campesino-militar se engendrou na clandestinidade e, portanto, no silencioso e discreto trabalho de formação militar e articulação política com as comunidades indígenas. Durante a década de 1980, os zapatistas organizaram-se e movimentaram-se discretamente, sigilosamente. É com o levante de 1994 que o Comitê Clandestino Revolucionário Indígena - Comando Geral do Exército Zapatista de Libertação Nacional se constituirá como o suposto porta-voz dos "sem voz" - aqueles segregados do espaço político mexicano. Acredito que algo daquele silêncio histórico de centenária resistência indígena - que não falava "do lugar que se 'espera' que ele fale" (Orlandi, 2007, p. 58) -, parece ressoar, prenhe de sentidos, na atual apraxia do silenciar zapatista.

\section{Bartleby: o escrivão ágrafo}

O homem é dono do que cala e escravo do que fala.

Freud

Cabe ainda indagar: é o silenciar zapatista, essa espécie de suspensão do falatório (este entendido no sentido que Heidegger ([1927] 2005) lhe confere: como a possibilidade de tudo entender, mas sem que aconteça uma efetiva compreensão), uma eficaz prática política? Para começar a responder essa questão, caberia precisar o termo: ao invés de caracterizar o silenciar como prática, prefiro defini-lo como apraxia, como uma forma de recusa em praticar/predicar. Desse modo, podemos trazer novamente Žižek, ainda que o filósofo mantenha um distanciamento crítico em relação ao zapatismo:

"o perigo não é passividade, mas pseudoatividade, ânsia de ser ativo e participar. As pessoas intervém o tempo todo, tentando "fazer alguma coisa", acadêmicos participam de debates sem sentido; a coisa realmente difícil é dar um passo atrás e retirar-se daquilo. Os que estão no poder muitas vezes preferem até uma participação crítica em vez do silêncio - só para nos envolver num diálogo, para se assegurar de 
que nossa passividade ameaçadora seja rompida. Contra esse modo interpassivo, em que somos ativos o tempo todo para assegurar que nada mudará realmente, o primeiro passo verdadeiramente decisivo é retirar-se para a passividade e recusar-se a participar. Esse primeiro passo limpa o terreno para uma atividade verdadeira, para um ato que mudará efetivamente as coordenadas da cena”. (Žižek, 2010, p. 37)

Para além dos zapatistas, o silenciar ou o gesto de recusa em participar remete a outros sujeitos subversivos que gostaria de mencionar: Bartleby e companhia, livro do catalão Enrique Vila-Matas, narra a trajetória de literatos que, subitamente, cessaram sua escrita (Rimbaud, Kafka, etc.). Todos eles tomados pela síndrome Bartleby.

Personagem inventada pelo escritor Melville, Bartleby, que trabalha como escriturário em Wall Street, profere o enunciado Preferia não fazer como resposta modalizada, mas insistente às ordens e demandas de seu chefe. Esse enunciado lembra o já citado oximoro pirrônico não afirmo que afirmo, pois funciona como recuo diante da injunção (a predicar/a praticar) ou, segundo Agamben (1993, p. 35.), é "potência de não escrever"[...] e "impotência que se vira para si própria".

$\mathrm{Ou}$, nas palavras de Deleuze

"PREFERIA NÃO. A fórmula tem variantes. Às vezes ela abandona o futuro do
pretérito e se torna mais seca: PREFIRO NÃO. I prefer not to do. Outras vezes,
nas última ocasiões em que surge, parece perder seu mistério ao reencontrar tal ou
qual infinitivo que a completa e que se engancha a to: "prefiro calar-me", "preferiria
não ser pouco razoável". [...] A fórmula germina e prolifera. A cada ocorrência, é o
estupor em torno de Bartleby, como se se tivesse ouvido o Indizível ou o Irrebatível.
E é o silêncio de Bartleby, como se tivesse dito tudo e de chofre esgotado a lingua-
gem. [PREFERIA NÃO] uma breve fórmula na aparência, quando muito um tique
localizado que ocorre por vezes. No entanto, o resultado, o efeito é o mesmo: cavar
na língua uma espécie de língua estrangeira e confrontar toda linguagem com
o silêncio, fazê-la cair no silêncio". (DELEUZE, 2011. p. $92,93,96$, grifos meus.)

Algo fica em suspenso por meio de uma subtração subjetiva. Com efeito, para Žižek (2010, p. 484.) “a ' política de Bartleby': mais do que resistir ativamente ao poder, o gesto de Bartleby, que 'prefere não fazer', suspende o investimento libidinal do sujeito no poder - o sujeito deixa de sonhar com o poder.". Subtração subjetiva, silenciar e apraxia, nessa ótica, seriam formas corrosivas de desobediência civil, fórmula arguta proposta por Pérez (2004) em El Silencio como forma de Resistencia Civil.

Para encerrar, cabe ainda ressaltar que não tomo o silenciar ou a apraxia como formas de resistência-revolta fora de dadas condições de produção discurso-ideológicas. Seus efeitos politicamente corrosivos ou subversivos dependem da conjuntura histórica em que aparecem. Sua eficácia é relativa às relações de força em jogo. Em termos outra ótica, poderia afirmar que são táticas mais ou menos felizes conforme a ocasião. Ou, então, que são formas de resistência que funcionam (melhor) quando em relação a outras práticas de resistência-revolta-revolução.

\section{Referências}

AGAMBEN. Giorgio. A comunidade que vem. Tradução de António Guerreiro. Lisboa: Editorial presença, 1993. 
AVILA, Dalia Ruiz. El silencio y su significación: Análisis del discurso zapatista.(s.d.) Disponível em: http://marting.stormpages.com/elsil.htm. Aceso em 11 de set, 2012. AUROUX, Sylvain. Filosofia da linguagem. Tradução de José Horta Nunes Campinas: Unicamp, 1998.

BARTHES, Roland. Aula. Tradução de Leyla Perrone-Moisés. São Paulo: Cultrix, 1978. BECK, Maurício. Aurora Mexicana - Processos de resistência-revolta-revolução em lutas populares da América Latina: o exemplo do discurso zapatista. 2010. 175 f. Tese (Doutorado em Letras) - UFSM, Santa Maria, 2010.

DINOUART, Abade. A Arte de Calar. [1771] Apresentação de Jean-Jacques Courtine e Claudine Haroche. Tradução de Luis Felipe Ribeiro. São Paulo: Martins Fontes, 2001. 80 p. EL-JAICK, Ana Paula. O ceticismo nos estudos da linguagem: sobre Contra os gramáticos, de Sexto Empírico. 2009. 197 f. Tese (Doutorado em Letras)- PUC do Rio de Janeiro, Rio de Janeiro, 2009.

EJÉRCITO ZAPATISTA DE LIBERACIÓN NACIONAL (EZLN) La Historia del Ruido y El Silencio. Disponível em:

http://palabra.ezln.org.mx/comunicados/1997/1997_02_14_a.htm. Acesso em 01 de nov, 2012.

. Quinta Declaración de la Selva Lacandona. [Julho de 1998]. Disponível em: http://palabra.ezln.org.mx/comunicados/1998/1998_07_a.htm. Acesso em 04 de nov, 2012.

KOHAN, Walter Omar. Do silêncio zapatista à euforia petista: fica algum lugar para nós? In: Revista Lugar Comum, n.18. Estudos de mídia, cultura e democracia, 2003, p.41-54. HAROCHE, Claudine; COURTINE, Jean-Jaques. Apresentação: Os Paradoxos do Silêncio. (2001) In: DINOUART, Abade. A Arte de Calar. Apresentação de Jean-Jacques Courtine e Claudine Haroche.. São Paulo: Martins Fontes, 2001. 80 p. Tradução de Luis Felipe Ribeiro

HEIDEGGER, Martin. Ser e Tempo. [1927] Petrópolis: Vozes, 2005. Tradução de Márcia de Sá Cavalcante Shuback.

MELVILLE, Herman. Bartleby, o escrivão.. Rio de Janeiro: José Olympio, 2007. Tradução de A. B. Pinhieros Lemos

NAVARRO, Luis Hernández. “A Força do silêncio” [1998] In: BUENROSTRO Y ARELLANO; OLIVEIRA, Ariovaldo Umbelino de. (org.) Chiapas: Construindo a Esperança. São Paulo: Paz e Terra/ México: La Jornada, 2002. Tradução de Maria José Rinaldo Barboza et al.

ORLANDI, Eni Pulcinelli. A Fala de muitos Gumes. (As Formas do Silêncio). In: A Linguagem e seu Funcionamento: As Formas do Discurso. 5. ed. Campinas: Pontes, 2009.

. As Formas do Silêncio: No movimento dos sentidos. 6. ed. Campinas: Unicamp, 2007. $182 \mathrm{p}$.

PÊCHEUX, Michel.(1983). O Discurso: estrutura ou acontecimento. 3. ed. Campinas: Pontes, 2002. Tradução de Eni Puccineli Orlandi.

. Só há causa daquilo que falha ou o inverno político francês: início de uma retificação. [1978] In: Semântica e Discurso: Uma Crítica à Afirmação do Óbvio., $3^{\mathrm{a}}$ ed., Campinas. Ed. Unicamp, 1997. Tradução de Eni Pulcinelli Orlandi, Lourenço Chacon Jurado Filho, Manoel Luiz Gonçalves Corrêa e Silvana Mabel Serrani.

PÉREZ, Luisa Ortiz. El Silencio Como Forma De Resistencia Civil. Análisis Del Discurso Del Ezln, 1997- 2001. In: Revista Venezolana de Economía y Ciencias Sociales, enero-abril, año/vol. 10, número 001, 2004, p. 109-127. 
TFOUNI, Fabio Elias Verdiani. O Interdito e o Silêncio: duas abordagens do impossível na linguagem. In: Linguagem em (Dis)curso - LemD, v. 8, n. 2, p. 353-371, maio/ago. 2008. VILA-MATAS, Enrique. Barterbly e companhia. São Paulo: Cosac Naify, 2004. Tradução de Maria Carolina de Araújo e Josely Vianna Baptista.

ŽIŽEK, Slavoj. A Visão em Paralaxe.. São Paulo Boitempo, 2008a. 507 p. Tradução de Maria Beatriz de Medina . Bem-vindo ao Deserto do Real! Cinco Ensaios sobre 11 de Setembro e Datas Relacionadas.. São Paulo: Boitempo, 2003. 191 Tradução de Paulo Cezar Castanheira . Em defesa das Causas Perdidas. Tradução de Maria Beatriz de Medina. São

Paulo: Boitempo, 2011.

. Viver no Fim dos Tempos.: Relógio D’Água Editores, 2010. Tradução de Miguel Serras Pereira. Lisboa 